\title{
The nutrition transition in Colombia over a decade: a novel household classification system of anthropometric measures
}

Diana C Parra ${ }^{1 *}$, Lora lannotti ${ }^{2}$, Luis F Gomez ${ }^{3}$, Helena Pachón ${ }^{4}$, Debra Haire-Joshu ${ }^{5}$ Olga L Sarmiento ${ }^{6}$, Anne Sebert Kuhlmann ${ }^{2}$ and Ross C Brownson ${ }^{7,8}$

\begin{abstract}
Background: Overweight and underweight increase the risk of metabolic impairments and chronic disease. Interventions at the household level require the diagnosis of nutritional status among family members. The aim of this study was to describe the prevalence and patterns of various anthropometric typologies over a decade in Colombia using a novel approach that considers all children in the household as well as the mother. This approach also allows identifying a dual burden of malnutrition within a household, where one child may be overweight and another one undernourished.

Methods: This study used data from the Demographic and Health Survey and the Colombian National Nutrition Survey [2000 $n=2,876,2005 n=8,598$, and $2010 n=11,349]$.

Four mutually exclusive household $(\mathrm{HH})$ anthropometric typologies - normal, undernourished, overweight/obese, and dual burden - were created. Anthropometric information of height-for-age Z-scores (HAZ) and body-mass-index-forage Z-scores (BMIz) in children under the age of $5 \mathrm{y}$, and on body mass index (BMI) in mothers, 18-49 y was used.

Results: Prevalence of overweight/obese HHs increased between 2000 (38.2\%) and 2010 (43.1\%) ( $p<0.05)$, while undernourished and dual burden HHs significantly decreased between 2005 (13.7\% and 10.6\%, respectively) and 2010 (3.5\% and 5.1\%, respectively) $(p<0.05)$. A greater increase of overweight/obesity was observed for the lowest quintile of wealth index (WI), with an increase of almost 10\% between 2000 and 2010, compared to 2\% and 4\% for the fourth and highest WI, respectively. Although in 2010 there is still a higher prevalence of overweight/obesity $\mathrm{HHs}$ in urban areas (43.7\%), the prevalence of overweight/obesity HHs in rural areas increased sharply between $2000(34.3 \%)$ and $2010(41.6 \%)(p<0.05)$.
\end{abstract}

Conclusion: The observed prevalence of dual burden households was not different from the expected prevalence. Results from this study indicate that although overweight/obesity continues to be more prevalent among highincome Colombian households, it is growing at a faster pace among the most economically disadvantaged.

Keywords: Overweight, Obesity, Nutrition transition, Stunting, Dual burden, Malnutrition, Colombia

\footnotetext{
* Correspondence: parrad@wusm.wustl.edu

${ }^{1}$ Program in Physical Therapy, School of Medicine, Washington University in

St. Louis, St. Louis, MO, USA

Full list of author information is available at the end of the article
} 


\section{Background}

Adult obesity is ranked among the top ten leading attributable risk factors of mortality in Latin American countries [1]. Similarly, undernutrition is the leading mortality risk factor in children ages under $1 \mathrm{y}$ in this region [1]. Despite worldwide improvement in life expectancy and reduction of child mortality, low birth-weight and childhood undernutrition continue to be significant problems in many countries from Latin America. Undernutrition has a negative impact on human capital and can lead to permanent and irreversible consequences that affect future generations [2,3]. Low birth weight and childhood undernutrition also increase the risk of developing obesity and co-morbidities in later life including metabolic syndrome, diabetes, and cardiovascular disease [4,5]. These risks are exacerbated by exposure to the increasingly prevalent obesogenic environment of countries undergoing rapid nutrition transition [6]. Colombia is experiencing a nutrition transition and has seen a steady increase in the average body mass index (BMI) of its population throughout the years; while at the same time childhood chronic undernutrition still persists, in both urban and rural areas [7].

Both underweight and overweight have devastating consequences for future health affecting the individual and society [2-5]. In the midst of this transition there is also an apparent paradox where undernutrition (e.g. based on anthropometry, biomarkers) and overnutrition (e.g. based on anthropometry) coexist within the same community and sometimes even within the same household or individual (i.e. a stunted child who is also overweight) [6,8-17]. This phenomenon is known as the dual burden of malnutrition $[18,19]$, which has been operationalized in various ways. Some studies have defined the dual burden household as the presence of underweight and overweight members within the same home [17]. Other studies have focused exclusively on the coexistence of childhood chronic undernutrition, typically among children $5 \mathrm{y}$ of age and younger, and overweight among mothers, particularly focusing on the youngest child-mother pair also known as stunted child - overweight mother (SCOM) [10]. In addition, most studies have focused on a particular region within a country or have only looked at national averages, not considering within-country differences and disparities. For instance, in Colombia, earlier research has shown that the national prevalence of SCOM was 5\% in 1995 [10], but regional variations within Colombia have not been examined and large disparities with higher prevalence among the most economically disadvantaged groups are anticipated. Given concomitant high rates of childhood undernutrition and maternal overweight/obesity in specific regions of the country (i.e. La Guajira, a northern state bordered by the Caribbean sea), vast differences in the prevalence of dual burden are expected [7]. Another study exploring the specific phenomenon of the dual burden of malnutrition (an underweight and an overweight member in the same household) is from the Antioquia state of Colombia. This study included 1,699 homes and documented the prevalence of dual burden to be as high as $12 \%$, with no significant differences between urban and rural areas [20].

A growing prevalence of overweight among disadvantaged populations has been reported in Brazil and Mexico [21-23]. It is likely that Colombia is following the same trend, but detailed information about this transition, including the dual burden of malnutrition taking into account regional differences is lacking. The last two decades in Colombia have implied profound economic, political and social transformations that have a direct effect on the nutritional status of the population. For instance, as a result of the Trade Agreement (TPA) with the United States (U.S.-Colombia Trade Agreement Now In Force, 2012), a greater access to highly processed foods, which has been found to be associated with obesity [24], is expected in the near future. It is likely that traditional diets and other cultural aspects related to eating habits have changed, as it has been the case in other countries from Latin America (Clark, Hawkes, Murphy, Hansen-Kuhn, \& Wallinga, 2012, Hawkes \& Thow, 2008) [25,26]. In addition, classification systems for anthropometric measures at the household level have been limited to only one child or specific members of the household. They also have not taken into account the possibility of concomitant stunting and overweight/obesity within one child, or all children in the household, or both; a recent phenomenon reported in countries undergoing nutrition transition $[27,28]$. It is important to document the current state of malnutrition problems in Colombia in particular among the most vulnerable groups including low income, rural populations, indigenous households, women and children.

Using data from the 2000, 2005, and 2010 Colombian Demographic and Health Survey (ENDS) and 20052010 National Nutrition Survey (ENSIN), which were conducted concomitantly in the years 2005 and 2010 [29-33], this study aims to document the changing patterns and prevalence of various anthropometric typologies at the household level, namely, normal, undernourished, overweight/obese, and dual burden. In addition, this study aims to document inequalities in the prevalence of these typologies by area of residence (rural versus urban) and wealth index using a novel household classification system of anthropometric measures. This study also explores regional differences by state, known as departamentos in Colombia.

\section{Methods}

\section{Study design}

We conducted a secondary data analysis of three crosssectional, nationally representative samples (2000, 2005 
and 2010) from Colombia [29-33]. In 2005 and 2010 we merged ENDS/ENSIN. Both of these surveys, ESIN and ENDS, interviewed the same households and the fieldwork was completed at the same time. The socio-demographic variables come from ENDS and the anthropometric measurements come from ENSIN. The surveys used a probabilistic, stratified, multistage, cross-sectional survey to obtain national and sub-regional representativeness (16 sub-regions), with oversampling of rural areas and low socioeconomic status (SES) groups. In 2000, 2005 and 2010, interviewers, mainly nutritionists, were selected to conduct anthropometric measurements following a rigorous standardized training averaging at least 5 weeks [29-33]. ENDS 2005 and 2010 included $99 \%$ of the urban and rural population. ENDS 2000 covered $98 \%$ of the national population as it excluded rural population from the San Andrés, Amazonas and Orinoco regions, due to difficulty in accessibility and high operational costs. Response rates for anthropometry were $93 \%$ in $200074 \%$ in 2005 , and $85 \%$ in 2010 [29-33].

\section{Data sets and sampling}

Households were used as the unit of analysis using individual measures to create the $\mathrm{HH}$ typologies, after merging relevant information from separate ENDS/ENSIN data sets (individual and household) [34]. For the purpose of the ENDS/ENSIN, a household is defined as a group of individuals consuming from the same food pot. Children with implausible values for weight, height and BMI $(>-/+5$ SD away from the median of the WHO reference population) [35] were excluded, going from 4,670 children to 4418 in 2000 , from 14,597 to 14,088 in 2005 , and from 18,578 to 18,101 in 2010 . Eligible HHs were those where there was at least one child $<5 \mathrm{y}$ and their mother between 18 and $49 \mathrm{y}$; if there was more than one eligible case (i.e. more than one mother living in the household with children less than 5 y) the entire household was excluded. These households were excluded on the basis that multi-family or extended family homes might look very different from nuclear or traditional families, it would have also impede us from using our classification system since it is limited to the information of one mother and their children. Multi-family homes represented ( $4 \%$ or 136 household of the eligible sample in $2000,6 \%$ or 664 households in 2005 , and $8.6 \%$ or 945 households in 2010. In 2000, out of 3,346 eligible HHs, 2,876 (86\%) were included in the analysis. In 2005, out of 10,939 eligible households, 8,598 (78.5\%) were included in the analysis. In 2010, out of 14,323 eligible HHs, 11,349 (79.2\%) were included in the analysis. Institutional Review Board approval for the analyses conducted in this study was not deemed necessary since there were no personal identifiers linking the data to individuals.

\section{Measures and variables}

During ENDS/ENSIN [29-33] weight and height were measured with standardized equipment. Weight was measured to the nearest $0.1 \mathrm{~kg}$ using a digital weighing scale (SECA model 770; Brooklyn, NY), participants were instructed to wear light clothing and remove shoes. Height was measured to the nearest $1.0 \mathrm{~cm}$ with a portable stadiometer (Shorr Productions, Onley, MD) and length was measured in children $2 \mathrm{y}$ or younger in a prone position, following established protocols $[35,36]$.

\section{Outcome variable}

Four mutually exclusive categories describing household anthropometric typologies were developed based on children's and maternal nutritional status (Table 1).

Nutritional status of children: HAZ and body-massindex-for-age Z-scores (BMIz) in children were calculated according to the WHO guidelines [35] using the WHO Anthro software (version 3.2.2, January 2011). All children $<5$ y from eligible households were classified as stunted $(\mathrm{HAZ}<-2 \mathrm{SD})$ versus not stunted $[9,10]$, and as overweight/obese (BMIz $>2 \mathrm{SD}$ ) versus not overweight/ obese [35]. BMIz scores were used because they are well suited for statistical analysis and provide a useful interpretation as well as a basis for international reference and comparison [37].

Table 1 Household anthropometric typologies (Mutually exclusive categories)

\begin{tabular}{|c|c|c|}
\hline $\begin{array}{l}\text { Household anthropometric } \\
\text { typology }\end{array}$ & Children's anthropometric status & Mother's BMI \\
\hline Normal & No stunting or obesity among any of the children & Normal BMI $18.5-24.9 \mathrm{~kg} / \mathrm{m}^{2}$ \\
\hline Undernourished & $\begin{array}{l}\text { At least one child is stunted }(\mathrm{HAZ}<-2) \text { and the remaining children are } \\
\text { either stunted or normal }\end{array}$ & $\begin{array}{l}\text { Underweight BMI }<18.5 \mathrm{~kg} / \mathrm{m}^{2} \text { or } \\
\text { Normal BMI } 18.5-24.9 \mathrm{~kg} / \mathrm{m}^{2}\end{array}$ \\
\hline Overweight/obese & $\begin{array}{l}\text { At least one child is overweight/obese }(\mathrm{BMl} z>2 \mathrm{SD}) \text { and the remaining } \\
\text { children are either overweight/obese or normal }\end{array}$ & $\begin{array}{l}\text { Normal BMI } 18.5-24.9 \mathrm{~kg} / \mathrm{m}^{2} \text { or } \\
\text { Overweight/obese } \mathrm{BMI} \geq 25 \mathrm{~kg} / \mathrm{m}^{2}\end{array}$ \\
\hline \multirow[t]{2}{*}{ Dual Burden } & $\begin{array}{l}\text { At least one child is stunted }(\mathrm{HAZ}<-2) \text { and the remaining children can be } \\
\text { either stunted, normal, overweight/obese, or stunted and overweight/obese }\end{array}$ & Overweight/obese BMI $\geq 25 \mathrm{~kg} / \mathrm{m}^{2}$ \\
\hline & $\begin{array}{l}\text { At least one child is overweight/obese }(\mathrm{BMI} z>2 \mathrm{SD}) \text { and the remaining children } \\
\text { can be either normal, overweight/obese, or stunted and overweight/obese }\end{array}$ & Underweight $\mathrm{BMI}<18.5 \mathrm{~kg} / \mathrm{m}^{2}$ \\
\hline
\end{tabular}


Nutritional status of mother: Body Mass Index (BMI) was calculated and classified using the following WHO cutoff points [38]: underweight (BMI $\left.<18.5 \mathrm{~kg} / \mathrm{m}^{2}\right)$, normal (BMI $18.5-24.9 \mathrm{~kg} / \mathrm{m}^{2}$ ), and overweight/obese $\left(\mathrm{BMI} \geq 25 \mathrm{~kg} / \mathrm{m}^{2}\right)$.

Taking into account all possible combinations of the anthropometric indicators used in this study, nineteen different typologies were identified (Table 2). However, despite finding nineteen possible combinations of anthropometric typologies, most of the typologies were demonstrated by a few prevalent situations including: undernourished HHs, represented by a normal mother $\&$ at least one stunted child with the remaining children normal; overweight/obese $\mathrm{HH}$, represented by an overweight/obese mother and all children normal; and dual burden, represented by an overweight/obese mother and at least one stunted child with the remaining children normal. Typologies were merged into others when it was deemed appropriate based on anthropometric indicators (HAZ, BMIz and BMI) and taking into account potential clustering of risk factors that could influence the family. For example, homes where the mother was overweight/ obese and the children were normal were merged with the overweight/obese typology. Homes where the mother was underweight and the children were normal were merged with the undernourished category. Homes were the mother was underweight and there were either stunted and obese children in the same household were merged

Table 2 Households anthropometric typologies* identified by year: 2000 ( $n=2,876 \mathrm{HHs}$ ), 2005 ( $\mathrm{n}=8,598 \mathrm{HHs}$ ), and 2010 ( $n=11,349$ HHs) (DHS/(ENDS/ENSIN Colombia)

\begin{tabular}{|c|c|c|c|c|}
\hline Household anthropometric typology & $\begin{array}{l}2000 \mathrm{n}(\%) \\
95 \% \text { C.I }\end{array}$ & $\begin{array}{l}2005 \text { n (\%) } \\
95 \% \text { C.I }\end{array}$ & $\begin{array}{l}2010 \text { n (\%) } \\
95 \% \text { C.I }\end{array}$ & Final category \\
\hline $\begin{array}{l}\text { Normal mother \& all children normal } \\
\text { (neither stunted nor underweight or obese) }\end{array}$ & $1,182(41.1) 39.2-43$ & $3,574(41.9) 40.4-43.3$ & $4,301(39.3) 38.1-40.4$ & Normal \\
\hline Underweight mother \& all children stunted & $0(0)$ & $0(0)$ & $0(0)$ & Undernourished \\
\hline Underweight mother \& all children normal & $62(2.0) 1.4-2.5$ & $283(3.4) 2.9-3.8$ & $312(2.9) 2.5-3.3$ & Undernourished \\
\hline $\begin{array}{l}\text { Underweight mother \& at least one stunted } \\
\text { child the rest are normal }\end{array}$ & $22(0.1) 0.0-0.1$ & $74(0.07) 0.0-0.1$ & $76(0.1) 0.0-0.1$ & Undernourished \\
\hline Normal mother \& all children stunted & $0(0)$ & $0(0)$ & $0(0)$ & Undernourished \\
\hline $\begin{array}{l}\text { Normal mother } \& \text { at least one stunted } \\
\text { child the remaining are normal }\end{array}$ & $310(11) 9.6-12$ & $801(9.3) 8.5-10.1$ & $862(6.6) 5.9-7.2$ & Undernourished \\
\hline Overweight/obese mother \& all children normal & $932(32.6) 30.7-34.4$ & $2,882(32.8) 31.4-34.2$ & $4,494(40.0) 38.4-40.7$ & $\begin{array}{l}\text { Overweight/ } \\
\text { obese }\end{array}$ \\
\hline $\begin{array}{l}\text { Overweight/obese mother \& all children } \\
\text { overweight/obese }\end{array}$ & $0(0)$ & $0(0)$ & $0(0)$ & $\begin{array}{l}\text { Overweight/ } \\
\text { obese }\end{array}$ \\
\hline $\begin{array}{l}\text { Overweight/obese mother \& at least one child } \\
\text { overweight/obese, the remaining are normal }\end{array}$ & $90(3.1) 2.4-3.7$ & $229(3.0) 2.2-3.1$ & 379 (3.3) $2.8-3.7$ & $\begin{array}{l}\text { Overweight/ } \\
\text { obese }\end{array}$ \\
\hline Normal mother \& all children overweight/obese & $0(0)$ & $0(0)$ & $0(0)$ & $\begin{array}{l}\text { Overweight/ } \\
\text { obese }\end{array}$ \\
\hline $\begin{array}{l}\text { Normal mother \& at least one child } \\
\text { overweight/obese, the remaining are normal }\end{array}$ & $68(2.4) 1.8-3.0$ & $178(2.4) 1.9-2.8$ & $212(2) 1.7-2.3$ & $\begin{array}{l}\text { Overweight/ } \\
\text { obese }\end{array}$ \\
\hline Overweight/obese mother \& all children stunted & $0(0)$ & $0(0)$ & $0(0)$ & Dual burden \\
\hline $\begin{array}{l}\text { Overweight/obese mother \& at least one stunted } \\
\text { child the remaining are normal }\end{array}$ & $196(6.6) 5.5-7.6$ & $544(6.4) 5.7-7.1$ & $660(5.1) 4.6-5.6$ & Dual burden \\
\hline $\begin{array}{l}\text { Overweight/obese mother \& all children stunted } \\
\text { and overweight/obese }\end{array}$ & $0(0)$ & $0(0)$ & $0(0)$ & Dual burden \\
\hline $\begin{array}{l}\text { Overweight/obese mother } \& \text { at least one } \\
\text { child stunted and overweight/obese, } \\
\text { the remaining are normal }\end{array}$ & $12(0.4) 0.0-0.6$ & $23(0.0)$ & $47(0.0)$ & Dual burden \\
\hline Underweight mother \& all children overweight/obese & $0(0)$ & $0(0)$ & $0(0)$ & Dual burden \\
\hline $\begin{array}{l}\text { Underweight mother \& at least one child } \\
\text { overweight/obese, the rest are normal }\end{array}$ & $2(0)$ & $9(0.0)$ & $6(0.0)$ & Dual burden \\
\hline $\begin{array}{l}\text { Underweight mother \& all children stunted } \\
\text { and overweight/obese }\end{array}$ & $0(0)$ & $0(0)$ & $0(0)$ & Dual burden \\
\hline $\begin{array}{l}\text { Underweight mother \& at least one child stunted } \\
\text { and overweight/obese, the rest are normal }\end{array}$ & $0(0)$ & $1(0)$ & $0(0)$ & Dual burden \\
\hline
\end{tabular}


with the dual burden typology, as stated by final category in Table 2.

\section{Household anthropometric typologies}

Normal Households: No stunting or obesity among any of the children and mother with normal BMI.

Undernourished Households: At least one child is stunted $(\mathrm{HAZ}<-2)$ and the remaining children are either stunted or normal and mother classified as normal (BMI $18.5-24.9 \mathrm{~kg} / \mathrm{m}^{2}$ ) or underweight (BMI $<18.5 \mathrm{~kg} / \mathrm{m}^{2}$ ).

Overweight/obese Households: At least one child is overweight/obese $(\mathrm{BMIz}>2 \mathrm{SD})$ and the remaining children are either overweight/obese or normal and mother classified as normal (BMI $18.5-24.9 \mathrm{~kg} / \mathrm{m}^{2}$ ) or overweight/obese (BMI $\left.>25 \mathrm{~kg} / \mathrm{m}^{2}\right)$.

Dual Burden Households: At least one child is stunted $(\mathrm{HAZ}<-2)$ and the remaining children can be stunted, normal, overweight/obese, or stunted and overweight/ obese (BMIz $>2 \mathrm{SD})$ and mother classified as underweight $\left(\mathrm{BMI}<18.5 \mathrm{~kg} / \mathrm{m}^{2}\right)$ or overweight/obese $(\mathrm{BMI}>$ $25 \mathrm{~kg} / \mathrm{m}^{2}$ ) or at least one child is overweight/obese (BMIz > 2SD) and the remaining children can be either normal, overweight/obese, or stunted and overweight/ obese. If the mother was classified as underweight and at least one child was stunted and the remaining children were normal, this household was included in the underweight typology. The only case in which this home was classified as dual burden was if any of the remaining children was overweight/obese or stunted and overweight/obese. The same was applicable for homes in which the mother was overweight/obese and at least one child was overweight/obese; they were only included in the dual burden typology if the remaining children were either stunted or stunted and overweight/obese.

\section{Independent variables}

Three household-level stratifying variables were used. The first was area of residence, classified as urban versus rural, based on the definition used in the DHS/ENDS protocols [29-33] as follows: a) urban areas are organized in blocks with clear streets and highways; they include capital cities and municipal main cities, whereas, b) rural areas are disperse and non-disperse areas, have sprawling and farming areas with no clearly defined streets, highways or roads, and generally do not have structured water and sewage systems. The second stratifying variable was wealth index (WI), ranging from 1 to 5 , where 1 was the poorest and 5 was the richest household [39]. The wealth index proposed by Rutstein and Johnson in 2004 [39] and developed for use in DHS was used in this study. WI assesses the weighted average in the household of a range of assets, such as television, type of flooring, water supply, refrigerator, electricity, radio, television, and domestic servant. The index is estimated using principal components analysis and is a continuous variable. Quintile categories of the index already calculated and included in the survey were used in this analysis. The last stratifying variable used was states of the country [39].

\section{Data analysis}

Data from ENDS/ENSIN 2000, 2005, and 2010 [29-33] were used to calculate the prevalence of household anthropometric typology by strata: WI, area of residence (urban versus rural), and state. For each one of the stratifying variables, 95\% confidence intervals were calculated to assess significance of the change in the prevalence of household anthropometric typology among the three years $(2000,2005,2010)$.

The expected versus the observed prevalence of the dual burden of malnutrition were calculated for this study following other international studies [40]. To estimate the expected prevalence of the dual burden at the household level, the prevalence of maternal overweight/ obesity was multiplied by the prevalence of stunted children and divided by one hundred. Finally, the expected prevalence was compared with the observed prevalence using a chi-square and obtaining a $\mathrm{p}$ value deemed significant at the 0.05 level.

GIS Arc-view [41] was used to graphically depict the transition of anthropometric typologies in the country from 2000, 2005 to 2010 using state layers. STATA 12 [42] was used to calculate weighted prevalence of anthropometric typology stratifying by WI, area of residence, and state. All analyses accounted for the complex sampling design and sampling weights using the command svy.

\section{Results}

Overall, prevalence of stunting ( $\mathrm{HAZ}<-2 \mathrm{SD})$ among children younger than five years was $18.5 \%, 95 \% \mathrm{CI}$ : $17.2 \%-19.2 \%, 16.3 \%$, $95 \%$ CI: $15.3 \%-17.1 \%$, and $14.9 \%$, 95\% CI: 13\%-15.6\%, in 2000, 2005 and 2010, respectively (data not shown) (p-test for trend $<0.05$ ). Prevalence of overweight/obesity (BMIz $>2 \mathrm{SD}$ ) among children was 5.7\%, $95 \%$ CI: $5.3 \%-6.1 \%$ in 2000, $4.5 \%$, 95\% CI: $3.2 \%$ $5.1 \%$ in 2005, and 5.2\%, 95 CI: $4.3 \%-6.2 \%$ in 2010 (p-test for trend $>0.05$ ). Prevalence of underweight (BMI $<18.5 \mathrm{~kg} /$ $\mathrm{m}^{2}$ ) among mothers ages 18 to 49 years, was $3.9 \%, 95 \%$ CI: $3.5 \%-4.6 \%, 4.7 \%$, 95\% CI: 4.3\%-5.1\%, and 3.9\%, 95\% CI: $3.1 \%-4.2 \%$ in 2000, 2005, and 2010, respectively (p-test for trend $>0.05$ ). Meanwhile, prevalence of overweight/obesity among mothers $\left(\mathrm{BMI} \geq 25 \mathrm{~kg} / \mathrm{m}^{2}\right)$ was $42.1 \%, 95 \% \mathrm{CI}$ : 41.2\%-43.5\%, $41.1 \%$ 95\% CI: $40 \%-42.5 \%$, and $46.8 \%$, 95\% CI: $45.7 \%-47 \%$ in 2000, 2005 and 2010, respectively (p-test for trend $<0.05)$. Significant differences in the average BMI of mothers were detected (24.8, $95 \%$ C.I: $24.6 \%-24.9 \%$ in 
2000, vs. 25.3 , $95 \%$ C.I: $25.2 \%-25.4 \%$ in 2010 ) (p-test for trend $<0.05$ ).

\section{Prevalence and patterns of household anthropometric typologies}

The percentage of homes classified within the overweight/obese typology increased significantly from 2000 (38.2\%, 95\% C.I.: $36.2 \%-40.1 \%)$ to 2010 (43.1\%, 95\% C.I.: 41.9\%-44.3\%) (p-value <0.05) (Additional file 1). Meanwhile the percentage of homes classified as undernourished significantly decreased between 2005 (13.7\%, 95\% C.I: $12.7 \%-14.6 \%)$ and 2010 (10.6\%, 95\% C.I: 9.9\%-11.4\%) (p-value $<0.05$ ). A similar pattern was observed for the dual burden typology $(6.5 \%$, 95\% C.I.: $5.8 \%-7.3 \%$ in 2005 versus $5.1 \%$, $95 \%$ C.I.: $4.5 \%-5.6 \%$ in 2010 ) (p-value $<0.05$ ). The observed prevalence of the dual burden in all three years was not significantly different from the expected prevalence (in $20007.1 \%$ vs $6.6 \% \mathrm{p}$ value for chi-square 0.98 , in $20056.5 \%$ vs $7.6 \%$ p value for chi-square 0.92 , and in $20105.1 \%$ vs. $6.6 \%$ ) p value for chi-square 0.84 .

\section{Prevalence and trends of household anthropometric typologies by area of residence}

The percentage of overweight/obese HHs was significantly higher among urban versus rural areas in $2005(\mathrm{P}<0.05)$ (Additional file 2). Although the prevalence of overweight/ obese HHs remains higher in urban versus rural areas in all three years, the rate of growth appears to be larger for rural areas. For instance, in 2010 the gap between urban and rural areas for all anthropometric typologies was decreasing: the prevalence of overweight/obese $\mathrm{HHs}$ in 2005 was $38.9 \%$ for urban and $33.3 \%$ for rural areas, and in 2010, the difference narrowed with $43.7 \%$ in urban areas versus $41.6 \%$ in rural areas. Likewise, a gap reduction was also seen for undernourished $\mathrm{HHs}(11.3 \%$ in urban and $18.9 \%$ in rural areas in 2005, versus $9.3 \%$ in urban and $14.1 \%$ in rural areas in 2010) and dual burden HHs (5\% in urban and 9.9\% in rural areas in 2005 versus $4.6 \%$ in urban and $6.1 \%$ in rural areas in 2010). Meanwhile, dual burden and undernourished typologies were significantly more prevalent among rural areas in 2000 and 2005 ( $<<0.05)$.

\section{Prevalence and trends of anthropometric typology households by WI}

The prevalence of overweight/obese HHs increased with WI across all three years, but in 2010 the gap between lowest and highest WI was smallest (Additional file 3). For instance, the prevalence of overweight/obese HHs in the lowest wealth quintile was $30.6 \%$ versus $43.9 \%$ in the highest quintile in 2000; meanwhile, the prevalence of overweight/obese $\mathrm{HHs}$ in the lowest wealth quintile was $39.6 \%$ versus $49.2 \%$ in the highest quintile in 2010 . Although the overweight/obesity typology continues to be more prevalent among the fourth and highest wealth quintile in all three years, the rate of increase between 2000 and 2010 is larger among households in the first (9 percentage points (pp)) and second wealth quintile (7.3 pp) compared to the fourth $(-0.8 \mathrm{pp})$ and fifth quintiles $(5.3 \mathrm{pp})$.

The prevalence of undernourished $\mathrm{HHs}$ decreased as WI increased (Additional file 4). Similar to the overweight/obese typology, prevalence is becoming more homogenous throughout the years as the gap between the lowest and the highest wealth quintile seems to be narrowing. For example, the prevalence of undernourished HHs in 2005 was $23.4 \%$ in the lowest wealth quintile and $4.3 \%$ in the highest wealth quintile, versus $15.7 \%$ in the lowest wealth quintile and $5.3 \%$ in the highest wealth quintile for the year 2010. Nevertheless, there are significant differences in the prevalence of undernourished between the lowest and the highest wealth quintiles, with almost three times higher prevalence among the poorest in 2010.

Similar to the undernourished typology, the prevalence of dual burden households decreased as WI increased (Additional file 5). The differences between wealth quintiles are more homogenous in the year 2010 compared to 2000 and 2005. In particular, there has been a significant reduction in the prevalence of dual burden for the lowest WI between 2005 and 2010.

\section{State variation in the prevalence of anthropometric typology households}

Within state variations across time are depicted in maps for overweight/obese (Figure 1, Figure 2), undernourished (Figure 3), and dual burden (Figure 4) HHs. The progression of the various anthropometric typologies between 2000, 2005 and 2010 are presented in the maps showing an overall increase of overweight/obese $\mathrm{HHs}$ and an overall reduction in the prevalence of undernourished and dual burden HHs. Regarding the overweight/obesity category, almost every state from Colombia experienced an increase in the percentage of overweight/obese households, but the states located in the south-east region saw the highest increase (Figure 2). In contrast, the prevalence of undernourished households decrease overtime across all states of Colombia, with the exception of the southern states of Amazonas and Vaupes, which actually saw an increase (Figure 3). Regarding the dual burden of malnutrition, all of the states of Colombia experienced a decrease in the prevalence overtime with the exception of the Northern state of la Guajira (Figure 4). For reference of the location of each state please refer to Figure 1.

\section{Discussion}

This study is among the first to document the nutrition transition in Colombia over a decade using objectively measured anthropometric data from large nationally 


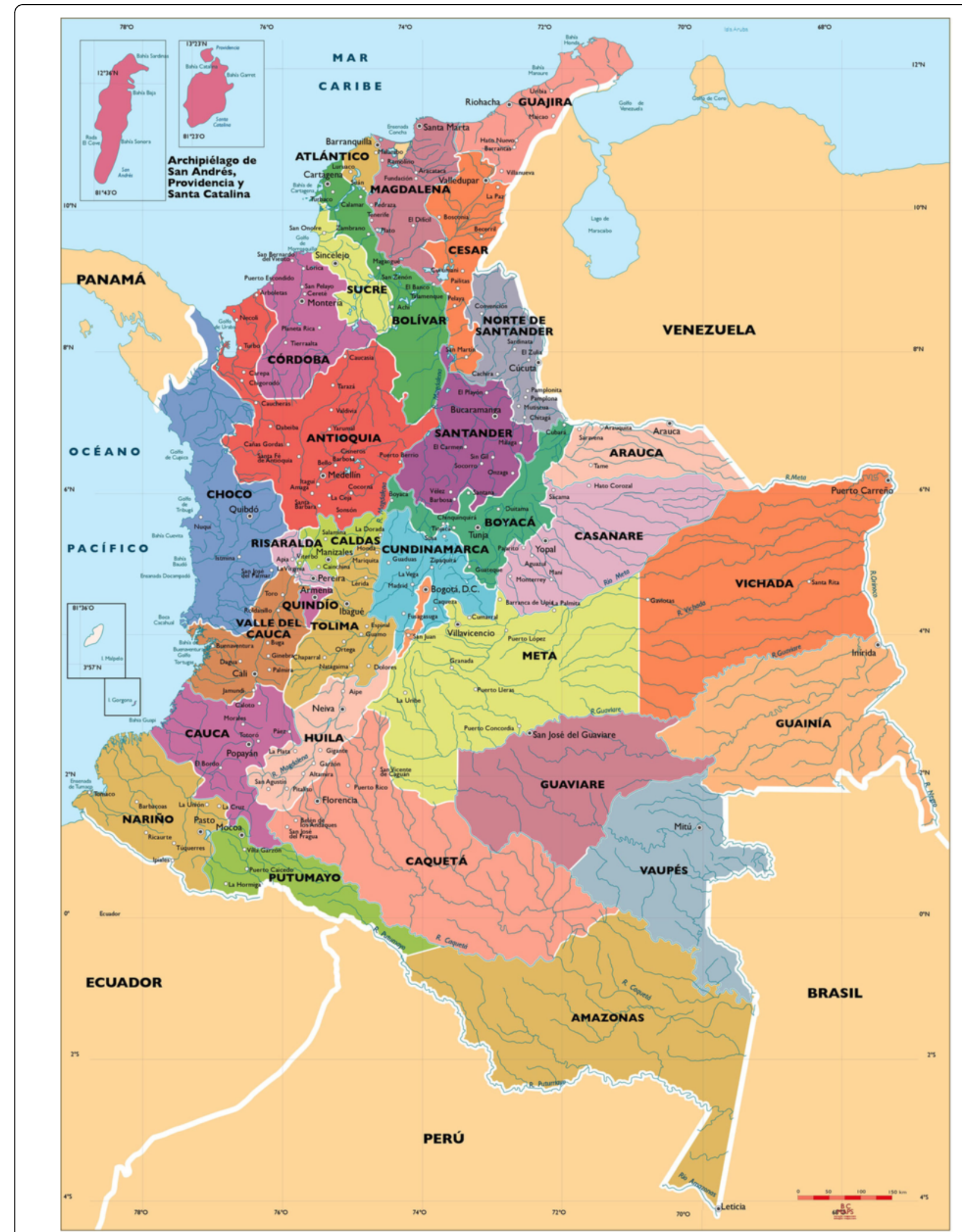

Figure 1 Map of Colombian States to use as reference for subsequent graphs. 


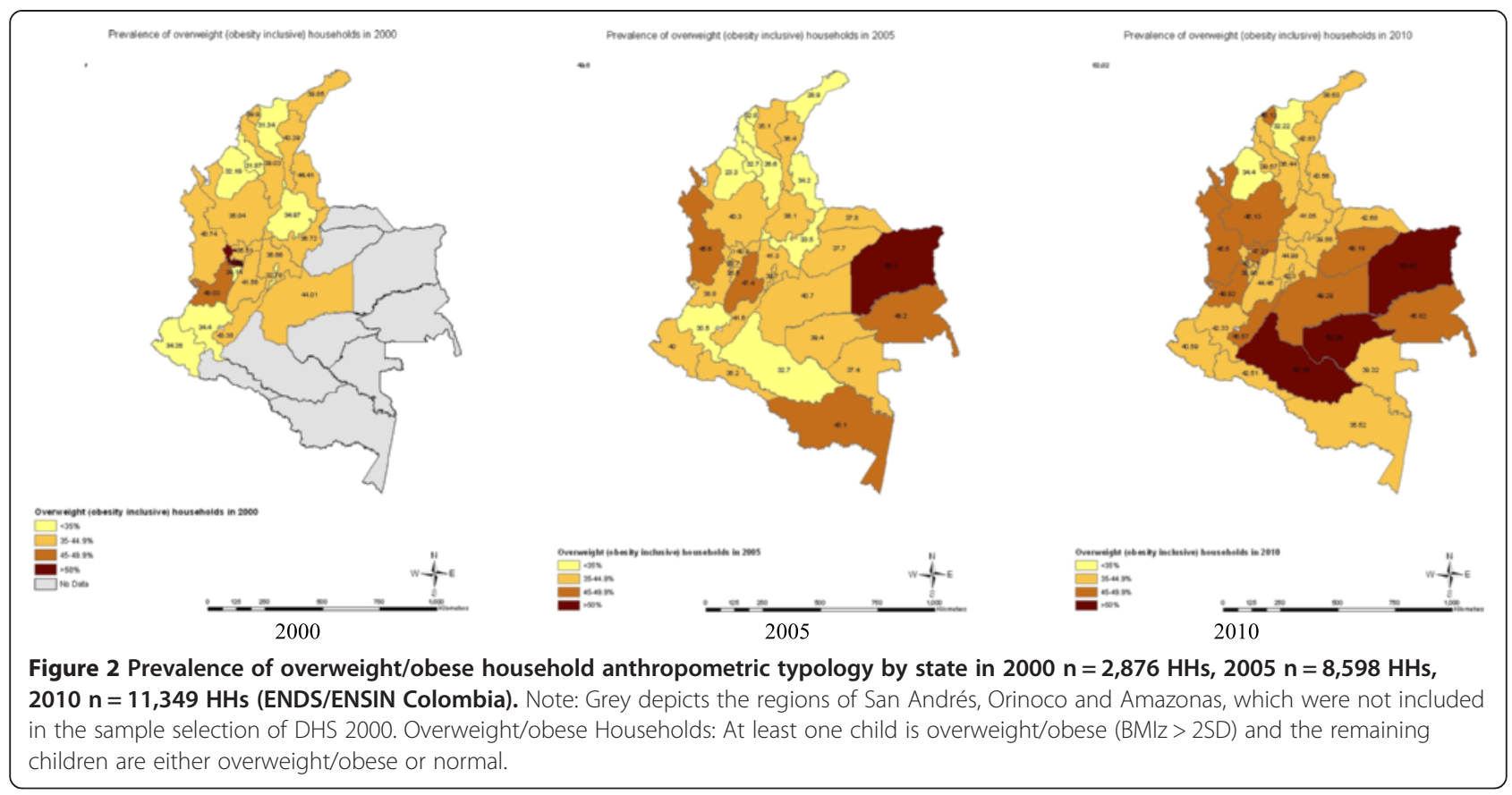

representative surveys. In addition, this study developed a novel classification system that considers all children in the household as well as their mother. This approach also allows identifying a double burden of malnutrition within a household, where one child may be overweight and another one undernourished. The current study provides important information regarding the nutrition transition in Colombia including the prevalence and extent of the dual burden of malnutrition at the state level and not only at the national or regional level [10]. Identifying the multiple typologies within households provides for the first time a diagnosis of the nutritional status of the dyads of children and mothers. Results from this study suggest that the changes in the nutrition transition in Colombia over the 10 y period are mainly demonstrated by two factors - increasing overweight/

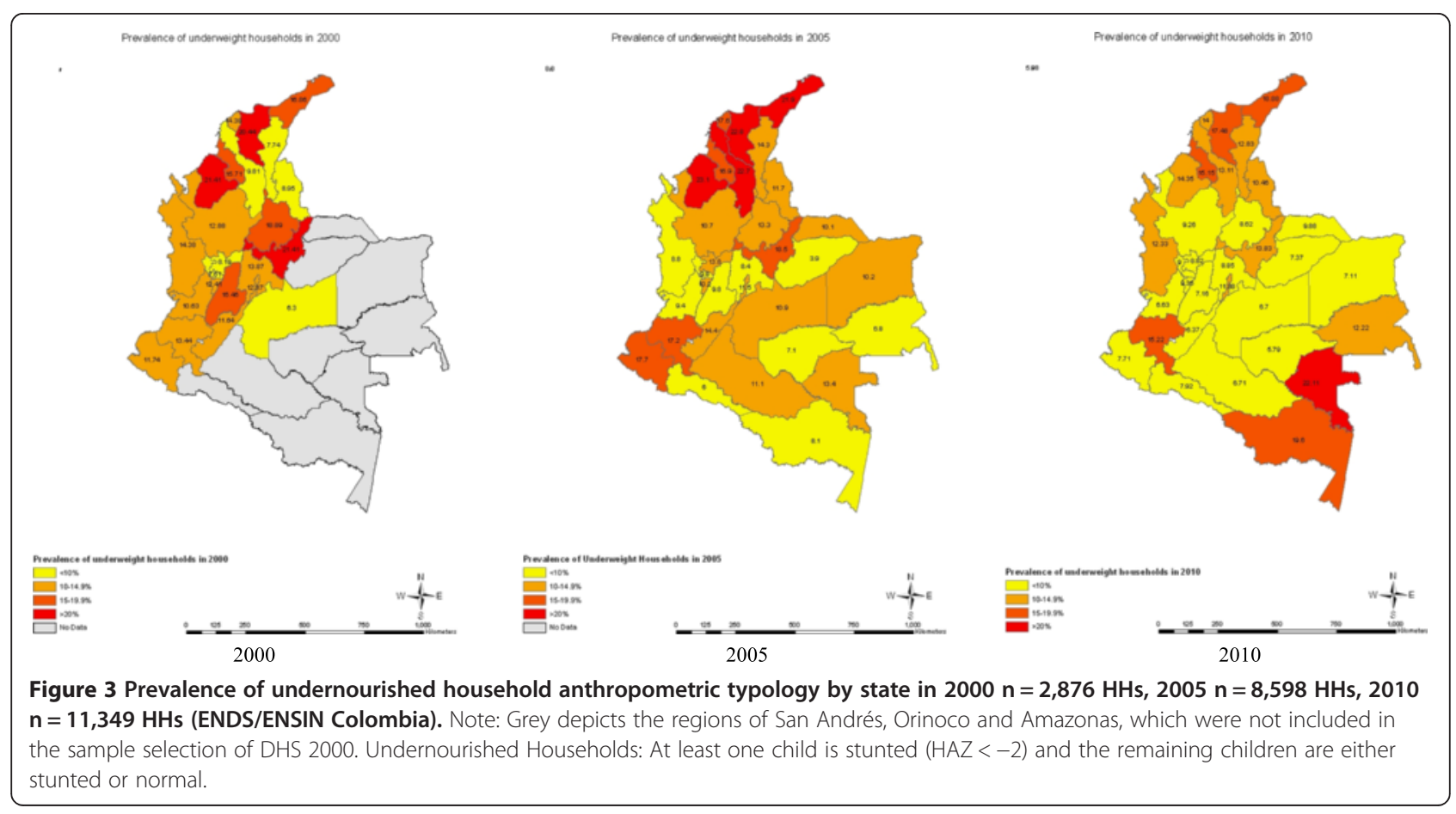




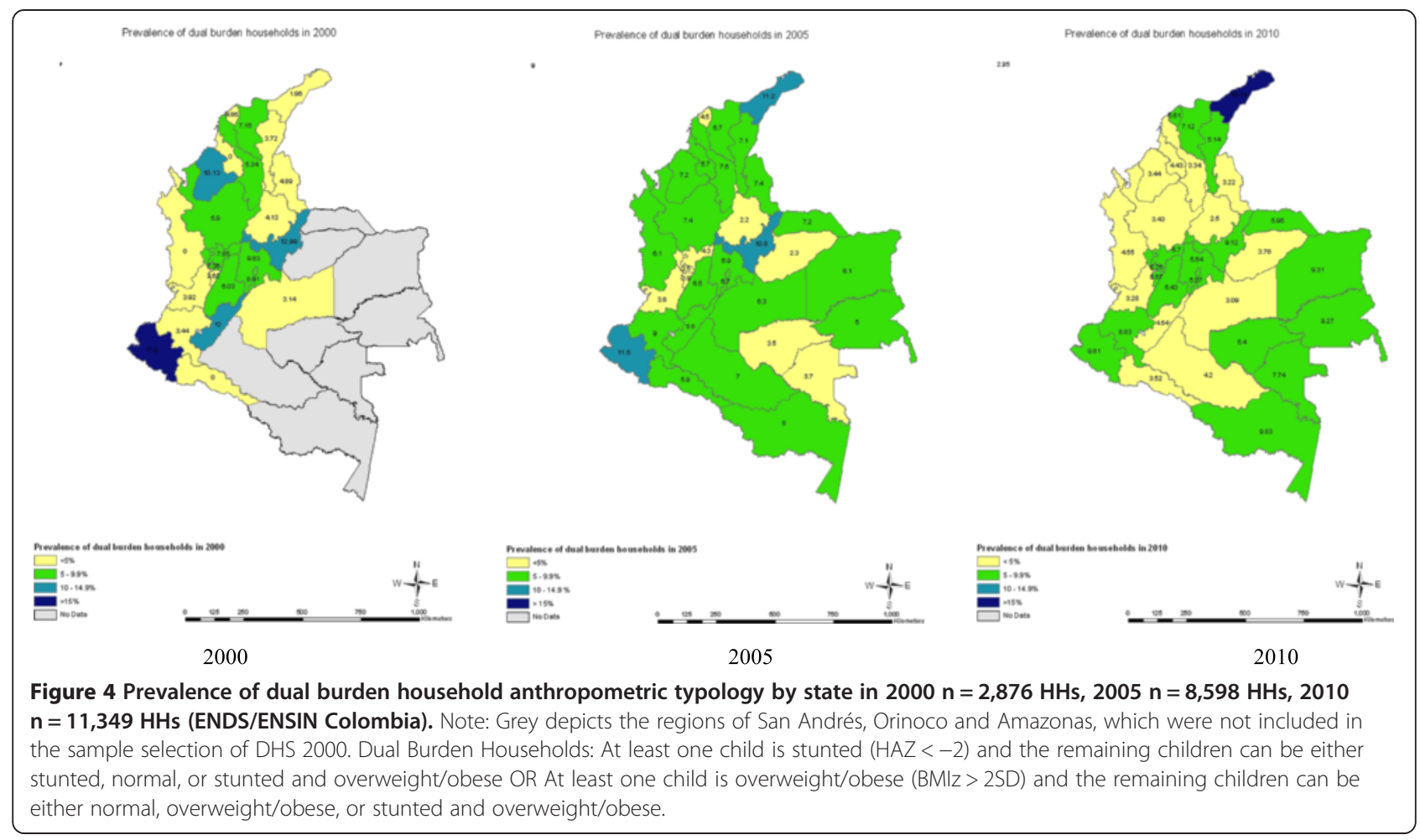

obesity in mothers and decreasing stunting in children. This pattern was confirmed by a decrease in the percentage of the population in the normal weight category and a shift towards the overweight/obese typology. Similar trends including the decrease in the dual burden have been reported in most countries from Latin America and the Caribbean undergoing a nutrition transition [43-50].

The prevalence of overweight/obese households was higher among high WI versus middle and lower WI households. However, there was a larger increase over time among lowest WI categories compared to the highest WI categories. This indicates that although overweight/obesity continues to be more prevalent among high-income populations, it is growing at a faster rate among the most economically disadvantaged as seen in other countries from Latin America including Brazil and Mexico [21-23]. The observed prevalence of dual burden across all three years in the Colombia surveys did not differ significantly from the expected prevalence [40]. However, states like La Guajira need closer attention, since it was the only state in which the prevalence of dual burden increased over time which may be related to the confluence of adverse socioeconomic conditions, public utility deficiencies, and political corruption [51,52], as well as a high prevalence of indigenous populations whose high prevalence of dual burden has been reported elsewhere [53-56].

This study found important state disparities of various anthropometric typologies for overweight/obese, undernourished and dual burden HHs. Regional differences must be considered when designing and implementing nutrition policies at the population level. For example, the Pacific region (i.e. Chocó and Cauca states) is marked by poverty and inequalities, as well the effects of a long lasting armed internal conflict which is higher than the burden experienced from these problems in other regions of the country [57]. Effects of the internal conflict that directly affect the nutritional status of the population are related to shortages of food supply and food security and have been documented in several reports by national and international agencies [58,59]. More than $90 \%$ of the population of the Pacific region is of African descent, which has been traditionally marginalized, undermined, and discriminated in the country, similarly to the indigenous population. This population has been subjected to conditions of poverty over many generations, which have directly affected their nutritional status [60]. The region occupies regular headlines in Colombian newspapers as the area with one of the worst prevalences of child undernutrition in the country [57]. However, evidence from the present study shows that the region is also suffering from a concomitant increase of overweight/obesity, in this case both problems could potentially be linked to conditions of poverty such as lack of access to basic sanitation, clean water and infrastructure, which have traditionally been associated with undernourishment [61], but also possibly to easy access and higher consumption of energy dense nutrient poor foods [62]. Higher or normal levels of BMI 
do not necessarily translate to good nutrition; in fact many micronutrient deficiencies can still exist even under conditions of overweight and obesity $[63,64]$. Recent studies, mainly from low and middle-income countries have documented the coexistence of anemia and obesity among the adult $[65,66]$ and child population [67]. According to the last Colombian nutrition survey in 2010, the Pacific region has one of the highest rates of anemia in the country with $32.2 \%$ among children 6 to 59 months, and 13\% among women 13 to 49 years old, compared to the national average of $27.7 \%$ and $7.6 \%$, respectively [7]. The maps produced in this paper highlight regional inequalities in the distribution of malnutrition problems in the country, in particular for the undernourished and dual burden typologies, which are higher in states with lower human development indexes and higher prevalence of unmet basic needs such as Amazonas and Orinoco. Further analysis need to be conducted to disentangle mechanisms of racial health inequalities with respect to underweight and dual burden households.

Some limitations of this study deserve mention. First, the use of secondary data brings the usual problems associated with this type of data, including the inability to obtain additional information directly from the respondents. Much of the information used in this study was self-reported and could be affected by social desirability bias [68]. Other types of measurement error could exist for anthropometric measures, however standardized international training was provided to the interviewers for all years of ENDS/ENSIN (2000, 2005, and 2010) and the likelihood of errors is minimal. A different sampling frame was used in 2000, by excluding the rural regions of San Andrés, Orinoco and Amazonas, which limits the reach of the conclusions. Finally, although the outcome variable created for this study offers a novel and comprehensive approach, it combines information from various anthropometric categories, which could have reduced the ability to detect true differences. Nonetheless, as mentioned earlier, the final four categories (normal, overweight/obesity, undernourished, dual burden $\mathrm{HHs}$ ) are driven only by a few prevalent anthropometric typologies.

Strengths of this study include the use of large national nutrition surveys that span a decade, providing rich information that allows producing a nutritional profile of the Colombian population through a period of profound economic, political and social changes. In addition, the new household classification system of anthropometric typologies developed in this study is an advancement over traditional methods since it allows the inclusion of all the children in the household and also of concomitant types of malnutrition including chronic undernutrition, overweight/obesity and dual burden at the individual level. This is the major innovation of the study and can have vast potential for assessing the population at the national level and for better targeting nutrition interventions and policies. Using information from publicly available data from Demographic and Health Surveys, it is possible for other countries from Latin America to assess the household level prevalence of malnutrition using this novel classification system. Doing so would allow for comparative studies throughout the region and establishing the prevalence of the dual burden of malnutrition at the household level, a phenomenon that still needs to be assessed and explored in some countries from the region.

\section{Conclusion}

Colombia is in the midst of a nutrition transition that is mirroring the changes occurring elsewhere in the world, such as an increase in the overweight/obese population and a general decrease in its chronically undernourished population. In general, some homogeneity in the distribution of anthropometric typologies by WI and area of residence (urban versus rural) was observed in this study. Although overweight/obesity continues to be more prevalent in urban versus rural areas, the rate of growth is higher among rural versus urban populations. Similar trends are seen for WI. While overweight/obesity increased with WI across all three years, a higher increase of overweight was observed for the lowest category of WI. A concerning finding documented in this study are the large regional inequalities in the prevalence of undernourished and dual burden HHs (Additional file 6: Graph 1, 3), and should be addressed by national, state, and local policies and programs that focus on increasing diet quality and promoting physical activity. The forthcoming 2015 national nutritional survey from Colombia will include the estimation of the dual burden at the household level in part based on the work developed in this study and similar efforts [69,70]. Although Colombia does not seem to have a prevalence of the dual burden of malnutrition beyond what would be normally expected based on the national prevalence [40], it is important for the food security policy of Colombia to consider the possibility of this phenomenon at the household level.

\section{Additional files}

Additional file 1: Household anthropometric typologies* by year $2000 \mathrm{n}=2,876 \mathrm{HHs}, 2005 \mathrm{n}=8,598 \mathrm{HHs}$, and $2010 \mathrm{n}=11,349 \mathrm{HHs}$ (ENDS/ENSIN Colombia).

Additional file 2: Household anthropometric typologies by area of residence (urban versus rural) in $2000 \mathrm{n}=\mathbf{2 , 8 7 6} \mathrm{HHs}, 2005 \mathrm{n}=8,598$ HHs, $2010 \mathrm{n}=11,349 \mathrm{HHs}$ (ENDS/ENSIN Colombia).

Additional file 3: Overweight/obese household anthropometric typology by WI in 2000 n=2,876 HHs, $2005 n=8,598 \mathrm{HHs}, 2010$ $\mathrm{n}=11,349 \mathrm{HHs}$ (ENDS/ENSIN Colombia). 


\section{Additional file 4: Undernourished household anthropometric typology by WI in2000 $n=2,876 \mathrm{HHs}, 2005 n=8,598 \mathrm{HHs}, 2010$ $\mathrm{n}=11,349 \mathrm{HHs}$ (ENDS/ENSIN Colombia).}

Additional file 5: Dual Burden household anthropometric typology by WI in $2000 \mathrm{n}=2,876 \mathrm{HHs}, 2005 \mathrm{n}=8,598 \mathrm{HHs}, 2010 \mathrm{n}=11,349 \mathrm{HHs}$ (ENDS/ENSIN Colombia).

Additional file 6: Graph 1. Prevalence of overweight/obese household anthropometric typology by state in $2000 n=2,876 \mathrm{HHs}, 2005 n=8,598$ HHs, $2010 \mathrm{n}=11,349 \mathrm{HHs}$ (ENDS/ENSIN Colombia). Graph 2. Prevalence of undernourished household anthropometric typology by state in 2000 $\mathrm{n}=2,876 \mathrm{HHs}, 2005 \mathrm{n}=8,598 \mathrm{HHs}, 2010 \mathrm{n}=11,349 \mathrm{HHs}$ (ENDS/ENSIN Colombia). Graph 3. Prevalence of dual burden household anthropometric typology by state in $2000 n=2,876 \mathrm{HHs}, 2005 n=8,598$ HHs, $2010 \mathrm{n}=11,349 \mathrm{HHs}$ (ENDS/ENSIN Colombia).

\section{Competing interests}

The authors declare that they have no competing interests.

\section{Authors' contributions}

DP conceived the study, drafted the initial manuscript, prepared all the datasets and completed all the analyses. RB, LFG, LI, DHJ, ASK, HP and OLS participated in the writing and interpretation of results and revisions of the manuscript. All of the authors made substantial contributions to the manuscript and interpretations of results. All authors approved the final version and agreed to be accountable for all aspects of the work.

\section{Acknowledgements}

The authors wish to thank everybody that was involved and provided useful comments and recommendations including Carlos Augusto Monteiro, Cesar Victora, Daniel Cohen, Felipe Lobelo, and Jaime Miranda. Special thanks to the Instituto Colombiano de Bienestar Familiar (ICBF) and PROFAMILIA, for providing support and allowing the use of the ENDS/ENSIN data sets to complete this study, in particular to Daniel Ayala who provided invaluable support and input in data management and analysis. Funding for this study was partially provided by an International Dissertation Scholarship from the Brown School to Diana Parra. In addition, Project GUIA funded part of the research assistantship time of the lead author through the Centers for Disease Control and Prevention contract U48/DP000060-01 (Prevention Research Centers Program). Helena Pachón's time was supported by an appointment to the Research Participation Program at the United States (US) Centers for Disease Control and Prevention (CDC) administered by the Oak Ridge Institute for Science and Education through an interagency agreement between the US Department of Energy and CDC.

\section{Author details}

'Program in Physical Therapy, School of Medicine, Washington University in St. Louis, St. Louis, MO, USA. ${ }^{2}$ George Warren Brown School of Social Work, Institute for Public Health, Washington University in St. Louis, St. Louis, MO, USA. ${ }^{3}$ Departamento de Medicina Preventiva y Social. Facultad de Medicina, Pontificia Universidad Javeriana, Bogotá, Colombia. ${ }^{4}$ Food Fortification Initiative, Atlanta, USA; Hubert Department of Global Health, Rollins School of Public Health, Emory University, Atlanta, USA. ${ }^{5}$ Center for Diabetes Translation Research and Center for Obesity Prevention \& Policy Research, Washington University in St. Louis, St. Louis, MO, USA. ${ }^{6}$ Department of Public Health, School of Medicine, Universidad de los Andes, Bogotá, Colombia. ${ }^{7}$ Prevention Research Center in St. Louis, Brown School, Washington University in St. Louis, St. Louis, MO, USA. ${ }^{8}$ Division of Public Health Sciences and Alvin J. Siteman Cancer Center, Washington University in St. Louis School of Medicine, St. Louis, MO, USA.

Received: 1 July 2014 Accepted: 5 December 2014

Published online: 16 February 2015

\section{References}

1. In Global Burden of Disease and Risk Factors. Edited by Lopez AD, Mathers CD, Ezzati M, Jamison DT, Murray CJL. Washington (DC); 2006.

2. Victora CG, Adair L, Fall C, Hallal PC, Martorell R, Richter L, Sachdev HS, Maternal, Child Undernutrition Study G. Maternal and child undernutrition: consequences for adult health and human capital. Lancet. 2008;371:340-57.
3. Waterlow JC. Linear growth development retardation in less developed countries. New York: Raven Press; 1988.

4. Barker DJ, Fall CH. Fetal and infant origins of cardiovascular disease. Arch Dis Child. 1993:68:797-9.

5. Eriksson JG, Forsen T, Tuomilehto J, Winter PD, Osmond C, Barker DJ. Catchup growth in childhood and death from coronary heart disease:longitudinal study. BMJ. 1999;318:427-31.

6. Rivera JA, Barquera S, Gonzalez-Cossio T, Olaiz G, Sepulveda J. Nutrition transition in Mexico and in other Latin American countries. Nutr Rev. 2004;62:S149-57.

7. Encuesta nacional de la Situacion Nutricional en Colombia 2010. In Book Encuesta nacional de la Situacion Nutricional en Colombia 2010, City:Bogota ICBF; 2011.

8. Barquera S, Peterson KE, Must A, Rogers BL, Flores M, Houser R, et al. Coexistence of maternal central adiposity and child stunting in Mexico. Int J Obes (Lond). 2007;31:601-7.

9. Garrett J, Ruel MT. The coexistence of child undernutrition and maternal overweight: prevalence, hypotheses, and programme and policy implications. Matern Child Nutr. 2005;1:185-196.

10. Garrett $\lrcorner$, Ruel MT. Stunted child-overweight mother pairs: prevalence and association with economic development and urbanization. Food Nutr Bull. 2005;26:209-21.

11. Doak CM, Adair LS, Bentley M, Monteiro C, Popkin BM. The dual burden household and the nutrition transition paradox. Int J Obes (Lond). 2005;29:129-36.

12. Doak CM, Adair LS, Monteiro C, Popkin BM. Overweight and underweight coexist within households in Brazil, China and Russia. The Journal of nutrition. 2000;130:2965-71.

13. FAO. The double burden of malnutrition: Case studies from six developing countries. In: Book The double burden of malnutrition: Case studies from six developing countries. vol. 84. City: Food and Agriculture Organization; 2006.

14. Khan NC, Khoi HH. Double burden of malnutrition: the Vietnamese perspective. Asia Pac J Clin Nutr. 2008;17 Suppl 1:116-8.

15. Khor GL, Sharif ZM. Dual forms of malnutrition in the same households in Malaysia-a case study among Malay rural households. Asia Pac J Clin Nutr. 2003;12:427-37.

16. Barros FC, Victora CG, Vaughan JP, Tomasi E, Horta BL, Cesar JA, et al. The epidemiological transition in maternal and child health in a Brazilian city, 1982-93: a comparison of two population-based cohorts. Paediatr Perinat Epidemiol. 2001;15:4-11.

17. Lee J, Houser RF, Must A, de Fulladolsa PP, Bermudez OI. Disentangling nutritional factors and household characteristics related to child stunting and maternal overweight in Guatemala. Econ Hum Biol. 2010;8:188-96.

18. Black RE, Allen LH, Bhutta ZA, Caulfield LE, de Onis M, Ezzati M, et al. Maternal and child undernutrition: global and regional exposures and health consequences. Lancet. 2008;371:243-60.

19. Caballero B. A nutrition paradox-underweight and obesity in developing countries. N Engl J Med. 2005;352:1514-6.

20. Benjumea MV, Estrada A, Alvarez MC. Dualidad de malnutricion en el hogar Antioqueno (Colombia): Bajo peso en los menores de 19 anos y exceso de peso en los adultos. Rev Chil Nutr. 2006;33:32-42.

21. Monteiro CA, Conde WL, Popkin BM. Income-specific trends in obesity in Brazil: 1975-2003. Am J Public Health. 2007;97:1808-12.

22. Fernald LC, Gutierrez JP, Neufeld LM, Gertler PJ. High Prevalence of Obesity Among the Poor in Mexico. JAMA. 2004;291:2544-5.

23. Jones-Smith JC, Gordon-Larsen P, Siddiqi A, Popkin BM. Is the burden of overweight shifting to the poor across the globe? Time trends among women in 39 low- and middle-income countries (1991-2008). Int J Obes. 2012;36:1114-20.

24. Canella DS, Levy RB, Martins AP, Claro RM, Moubarac JC, Baraldi LG, et al. Ultra-processed food products and obesity in Brazilian households (2008-2009). PLoS One. 2014;9:e92752.

25. Clark SE, Hawkes C, Murphy SM, Hansen-Kuhn KA, Wallinga D. Exporting obesity: US farm and trade policy and the transformation of the Mexican consumer food environment. International journal of occupational and environmental health. 2012;18:53-65.

26. Hawkes C, Thow AM. Implications of the Central America-Dominican Republic-Free Trade Agreement for the nutrition transition in Central America. Revista panamericana de salud publica = Pan American journal of public health. 2008;24:345-360. 
27. Popkin BM. Global nutrition dynamics: the world is shifting rapidly toward a diet linked with noncommunicable diseases. Am J Clin Nutr. 2006;84:289-98.

28. Fernald LC, Neufeld LM. Overweight with concurrent stunting in very young children from rural Mexico: prevalence and associated factors. Eur J Clin Nutr. 2007;61:623-32

29. Encuesta Nacional de la Situación Nutricional en Colombia - ENSIN 2005. In Book Encuesta Nacional de la Situación Nutricional en Colombia - ENSIN 2005. City:Bogota Instituto Colombiano de Bienestar Familiar (ICBF); 2005.

30. Encuesta Nacional de Demografia y Salud - ENDS 2005. In Book Encuesta Nacional de Demografia y Salud - ENDS 2005. City: Bogota. Profamilia; 2005.

31. Sargeant LA, Wareham NJ, Bingham S, Day NE, Luben RN, Oakes S, et al. Vitamin $C$ and hyperglycemia in the European Prospective Investigation into Cancer-Norfolk (EPIC-Norfolk) study: a population-based study. Diabetes Care. 2000;23:726-32.

32. Encuesta Nacional de Demografia y Salud - ENDS 2010. In Book Encuesta Nacional de Demografia y Salud - ENDS 2010. City: Bogota Profamilia; 2010.

33. Encuesta Nacional de la Situación Nutricional en Colombia - ENSIN 2010. In Book Encuesta Nacional de la Situación Nutricional en Colombia - ENSIN 2010. City: Bogota, Instituto Colombiano de Bienestar Familiar (ICBF); 2010.

34. Parra D. The Nutrition Transition in Colombia: Underweight, Overweight and the Dual Burden of Malnutrition. Washington University in St. Louis: Social Work; 2013.

35. WHO. Child Growth Standards based on length/height, weight and age. Acta Paediatr Suppl. 2006:450:76-85

36. de Onis $M$, Habicht JP. Anthropometric reference data for international use: recommendations from a World Health Organization Expert Committee. The American journal of clinical nutrition. 1996;64:650-8.

37. Must A, Anderson SE. Body mass index in children and adolescents: considerations for population-based applications. Int J Obes (Lond). 2006:30:590-4.

38. WHO. Obesity: preventing and managing the global epidemic. Report of a WHO Consultation. In: Book Obesity: preventing and managing the global epidemic. Report of a WHO Consultation. City: Geneva, World Health Organization; 2000.

39. Rutstein SO, Johnson K. The DHS Wealth Index. In: Book The DHS Wealth Index. City: London, ORC Macro; 2004.

40. Dieffenbach $\mathrm{S}$, Stein AD. Stunted child/overweight mother pairs represent a statistical artifact, not a distinct entity. The Journal of nutrition. 2012;142:771-3.

41. ESRI. Arc GIS: Release 10. In: Book Arc GIS: Release 10 (Editor ed.^eds.), 10 edition. City: Environmental Systems Research Institute; 2011.

42. StataCorp. Stata Statistical Software: Release 14. In Book Stata Statistical Software: Release 14. 13 edition. StataCorp LP; 2013.

43. Albala C, Vio F, Kain J, Uauy R. Nutrition transition in Latin America: the case of Chile. Nutr Rev. 2001;59:170-6

44. Colon-Ramos U, Perez-Cardona CM, Monge-Rojas R. Socio-demographic, behavioral, and health correlates of nutrition transition dietary indicators in San Juan, Puerto Rico. Revista panamericana de salud publica = Pan American journal of public health. 2013;34:330-5

45. Piperata BA, Spence JE, Da-Gloria P, Hubbe M. The nutrition transition in amazonia: rapid economic change and its impact on growth and development in Ribeirinhos. Am J Phys Anthropol. 2011;146:1-13.

46. Popkin BM, Adair LS, Ng SW. Global nutrition transition and the pandemic of obesity in developing countries. Nutr Rev. 2012;70:3-21.

47. Prentice AM. Obesity in emerging nations: evolutionary origins and the impact of a rapid nutrition transition. Nestle Nutrition workshop series Paediatric programme. 2009;63:47-54. discussion 54-47, 259-268.

48. Riosmena F, Frank R, Akresh IR, Kroeger RA. U.S. Migration, Translocality, and the Acceleration of the Nutrition Transition in Mexico. Annals of the Association of American Geographers Association of American Geographers. 2012;102:1209-18

49. Rueda-Clausen CF, Silva FA, Lopez-Jaramillo P. Epidemic of overweight and obesity in Latin America and the Caribbean. Int J Cardiol. 2008;125:111-2.

50. Uauy R, Albala C, Kain J. Obesity trends in Latin America: transiting from under- to overweight. The Journal of nutrition. 2001;131:893S-9S.

51. La Guajira 2012: Estado de avance de los Objetivos de Desarrollo del Milenio. In Book La Guajira 2012: Estado de avance de los Objetivos de Desarrollo del Milenio. City: Bogota. PROGRAMA DE LAS NACIONES UNIDAS PARA EL DESARROLLO PNUD; 2012
52. Gamarra Vergara JR. Pobreza, corrupción y participación política: una revisión para el caso colombiano. In: Book Pobreza, corrupción y participación política: una revisión para el caso colombiano, vol. 70. City: Bogota, Banco de la Republica; 2006.

53. Ruben AR. Undernutrition and obesity in indigenous children: epidemiology, prevention, and treatment. Pediatr Clin N Am. 2009;56:1285-302.

54. Bustos $\mathrm{P}$, Munoz S, Vargas $\mathrm{C}$, Amigo H. Evolution of the nutritional situation of indigenous and non-indigenous Chilean schoolchildren. Ann Hum Biol. 2009;36:298-307.

55. Leite MS, Santos RV, Coimbra Jr CE. [Seasonality and nutritional status of indigenous peoples: the case of Wari' in Rondonia State, Brazil]. Cad Saude Publica. 2007:23:2631-42

56. Rivera JA, Sepulveda Amor J. Conclusions from the Mexican National Nutrition Survey 1999: translating results into nutrition policy. Salud Publica Mex. 2003;45 Suppl 4:S565-75.

57. Cuartas-Rodríguez P. Afrocolombianos siguen en el olvido. In: Book Afrocolombianos siguen en el olvido. City: Bogota: El Espectador; 2012.

58. Trujillo M. Necesidades alimentarias de las familias en situación de desplazamiento. In Book Necesidades alimentarias de las familias en situación de desplazamiento. City: Bogota; 1999.

59. ICBF. Seguridad Alimentaria para población desplazada. In Book Seguridad Alimentaria para población desplazada. City: Bogota; 2002

60. DANE. Análisis Regional De Los Prinicipales Indicadores Sociodemográficos De La Comunidad Afrocolombiana e Indígena a Partir De La Información Del Censo General. In: Book Análisis Regional De Los Prinicipales Indicadores Sociodemográficos De La Comunidad Afrocolombiana E Indígena A Partir De La Información Del Censo General. City: Bogota: Departamento Administrativo Nacional de Estadística; 2005.

61. Petrou S, Kupek E. Poverty and childhood undernutrition in developing countries: a multi-national cohort study. Soc Sci Med. 2010;71:1366-73.

62. Análisis de la situación de la pobreza infantil en Colombia. In Book Análisis de la situación de la pobreza infantil en Colombia. City: Bogota Escuela de Gobierno Alberto Lleras Camargo de la Universidad de los Andes para el Fondo de Naciones Unidas para la Infancia (Unicef); 2012.

63. Drewnowski A, Popkin BM. The nutrition transition: new trends in the global diet. Nutr Rev. 1997:55:31-43.

64. Kordas K, Fonseca Centeno ZY, Pachon H, Jimenez Soto AZ. Being overweight or obese is associated with lower prevalence of anemia among Colombian women of reproductive age. The Journal of nutrition. 2013;143:175-81.

65. Batista Filho M, Souza Al, Miglioli TC, Santos MC. [Anemia and obesity: a paradox of the nutritional transition in Brazil]. Cad Saude Publica. 2008;24 Suppl 2:S247-57.

66. Eckhardt CL, Torheim LE, Monterrubio E, Barquera S, Ruel MT. The overlap of overweight and anaemia among women in three countries undergoing the nutrition transition. Eur J Clin Nutr. 2008;62:238-46.

67. Nead KG, Halterman JS, Kaczorowski JM, Auinger P, Weitzman M. Overweight children and adolescents: a risk group for iron deficiency. Pediatrics. 2004:114:104-8.

68. Stuart GS, Grimes DA. Social desirability bias in family planning studies: a neglected problem. Contraception. 2009;80:108-12.

69. Garcia S, Sarmiento OL, Forde I, Velasco T. Socio-economic inequalities in malnutrition among children and adolescents in Colombia: the role of individual-, household- and community-level characteristics. Public Health Nutr. 2013;16:1703-18

70. Sarmiento OL, Ramirez A, Kutschbach BS, Pinzon PL, Garcia S, Olarte AC, et al. Nutrition in Colombian pregnant women. Public Health Nutr. 2012;15:955-63. 